\title{
Clinical Needs of Patients with Problem Drug Use
}

\author{
Antoinette Krupski, PhD, Imara I. West, MPH, Meredith C. Graves, PhD, \\ David C. Atkins, PhD, Charles Maynard, PhD, Kristin Bumgardner, BS, \\ Dennis Donovan, PhD, Richard Ries, MD, and Peter Roy-Byrne, MD
}

Introduction: Illicit drug use is a serious public health problem associated with significant co-occurring medical disorders, mental disorders, and social problems. Yet most individuals with drug use disorders have never been treated, though they often seek medical treatment in primary care. The purpose of this study was to examine the baseline characteristics of people presenting in primary care with a range of problem drug use severity to identify their clinical needs.

Methods: We examined sociodemographic characteristics, medical and psychiatric comorbidities, drug use severity, social and legal problems, and service utilization for 868 patients with drug problems. These patients were recruited from primary care clinics in a medical safety net setting. Based on Drug Abuse Screening Test results, individuals were categorized as having low, intermediate, or substantial/severe drug use severity.

Results: Patients with substantial/severe drug use severity had serious drug use (opiates, stimulants, sedatives, intravenous drugs); high levels of homelessness (50\%), psychiatric comorbidity (69\%), and arrests for serious crimes (24\%); and frequent use of expensive emergency department and inpatient hospitals. Patients with low drug use severity were primarily users of marijuana, with little reported use of other drugs, less psychiatric comorbidity, and more stable lifestyles. Patients with intermediate drug use severity fell in between the substantial/severe and low drug use severity subgroups on most variables.

Conclusions: Patients with the highest drug use severity are likely to require specialized psychiatric and substance abuse care, in addition to ongoing medical care that is equipped to address the consequences of severe/substantial drug use, including intravenous drug use. Because of their milder symptoms, patients with low drug use severity may benefit from a collaborative care model that integrates psychiatric and substance abuse care in the primary care setting. Patients with intermediate drug use severity may benefit from selective application of interventions suggested for patients with the highest and lowest drug use severity. Primary care safety net clinics are in a key position to serve patients with problem drug use by developing a range of responses that are locally effective and that may also inform national efforts to establish patient-centered medical homes and to implement the Affordable Care Act. (J Am Board Fam Med 2015;28:605-616.)

Keywords: Comorbidity; Delivery of Health Care, Integrated; Drug Abuse; Health Care Costs; Primary Health Care

Illicit drug use is a serious public health problem with a large economic impact. ${ }^{1}$ There is high comorbidity between drug use disorders and both medical ${ }^{2,3}$ and mental health ${ }^{4}$ disorders, and drug use is commonly associated with a host of social problems such as homelessness, ${ }^{5}$ criminal justice involvement, ${ }^{6}$ and un-

This article was externally peer reviewed.

Submitted 2 January 2015; revised 26 February 2015; accepted 2 March 2015.

From the Department of Psychiatry and Behavioral Sciences, School of Medicine, University of Washington at Harborview Medical Center, Seattle (AK, IIW, MCG, DCA, KB, DD, RR, PR-B); the Department of Health Services, University of Washington School of Public employment. ${ }^{5}$ Despite this substantial disability and comorbidity, most individuals with drug use disorders have never been treated. ${ }^{2}$ This finding underscores the importance of the detection and referral roles of primary care physicians in the treatment of individuals with substance use disorders, who are often seen in

Health, Seattle (CM); and the Alcohol \& Drug Abuse Institute, University of Washington, Seattle (DD).

Funding: This study was funded by the National Institute on Drug Abuse (grant no. R01 DA026014 to PR-B).

Conflict of interest: RR reported receiving financial support outside the submitted work from Janssen Pharmaceuticals Inc., Alkermes, and Reckitt Benckiser Pharamaceutical Inc. PR-B reported receiving financial support outside the sub- 
primary care because of their heightened prevalence of medical conditions. ${ }^{3}$

The Affordable Care Act (ACA) has established a number of mechanisms designed to promote personcentered care. These changes greatly expand the responsibilities of primary care providers, especially given the ACA's expectations for better outcomes and reduced costs for those with comorbid conditions. ${ }^{7}$ Yet very little is known about individuals with problem drug use who present in primary care; most information about this population comes from national surveys, ${ }^{2,4}$ studies of treatment-seeking populations, ${ }^{3,5}$ or studies conducted in emergency departments (EDs). ${ }^{8}$

To address this gap, this study was designed to take advantage of a randomized controlled trial that examined the impact of a brief intervention for people with problem drug use in a safety-net primary care setting, where patients with socioeconomic disadvantage often associated with drug use may be seen. ${ }^{9,10}$ Our goal was to examine baseline characteristics of the 868 patients with problem drug use to identify their clinical needs. This information can serve as a guidepost for primary care physicians who must perform a rapid needs assessment of patients they serve and determine how to use the limited resources that they might have.

\section{Methods}

\section{Participants}

All 868 participants were recruited between April 2009 and September 2012 from the waiting rooms of 7 primary care clinics in a safety net medical system in Seattle, Washington ${ }^{9,10}$; $86.4 \%$ of participants came from 3 of these clinics. Exploratory analyses revealed that the full range of drug use severity was represented in each of these clinics, including 1 clinic that spe-

mitted work as the Editor-in-Chief of Depression and Anxiety, FournalWatch Psychiatry, and UpToDate Psychiatry, and receiving stock options for consultation to Valant Medical Solutions (a behavioral health electronic medical record company). No other conflicts of interest have been reported.

Disclaimer: The views expressed reflect those of the authors and do not necessarily reflect the official views of the National Institute on Drug Abuse or the National Institutes of Health.

Corresponding author: Antoinette Krupski, PhD, Department of Psychiatry and Behavioral Sciences, University of Washington, Box 359911, 325 9th Ave, Seattle, WA 98104 (E-mail: krupski@uw.edu). cialized in human immunodeficiency virus (HIV) and infectious disease, which contributed approximately $7 \%$ of participants to this study. An analysis of variance comparing mean 10 -item Drug Abuse Screening Test (DAST-10) ${ }^{11}$ scores across each of the 7 sites revealed a significant site effect $(P<.001)$; post hoc Tukey analyses indicated that the mean DAST-10 scores of participants at 1 of the 3 large sites were higher than those at the other 2 large sites. Because the full range of drug use severity was represented in each of the clinics, because the clinics were reflective of the diverse patient populations served by this safety net medical system, and because we had no reason to believe that the larger concentration of participants with higher drug use severity at 1 of the sites would affect the overall relationship between DAST-10 scores and baseline characteristics-the primary purpose of this study - we felt justified in combining data across sites.

Included in the study were adults aged $\geq 18$ years who acknowledged using an illegal drug or a prescription medication for nonmedical reasons at least once in the 3 months before screening; were currently receiving care in the primary care clinic and planned to continue such care for the next year; spoke English and were able to read and understand screening and consent forms (sixth grade literacy); and had phone or E-mail access to facilitate scheduling follow-up assessments. Excluded were individuals who attended formal substance abuse treatment in the past month (excluding self-help groups such as Narcotics Anonymous). In addition, we excluded individuals who had imminent high suicide risk, life-threatening medical illness, severe cognitive impairment, or active psychosis to ensure participants were capable of providing informed consent, able to fully comprehend the intervention, and were considered "safe" (ie, to not be in a life-threatening status). All participants gave written, informed consent and received a $\$ 25$ gift card for completing study procedures at baseline. The study was approved by the University of Washington Institutional Review Board and an independent data and safety monitoring board.

\section{Measures}

Participants were sorted into 3 subgroups based on their DAST-10 scores: low drug use severity, de- 
fined as a DAST-10 score of 1 or 2; intermediate drug use severity, defined as a score of 3 to 5 ; and substantial/severe drug use severity, defined as a score of 6 to $10 .{ }^{12}$ Drug use severity corresponds to the extent of consequences related to drug misuse and also maps to treatment recommendations that correspond to the American Society of Addiction Medicine placement criteria, such that a DAST-10 score of 1 or 2 corresponds to a treatment recommendation for brief counseling; a score of 3 to 5 corresponds to a recommendation for outpatient or intensive outpatient services; a score of 6 to 8 corresponds to a recommendation for intensive outpatient or residential/inpatient services; and a score of 9 or 10 corresponds to a recommendation for residential/inpatient services or medically managed intensive inpatient services. ${ }^{12}$

Participants also were characterized along a dimension of psychiatric severity as measured by the Addiction Severity Index-Lite (ASI) psychiatric composite score, which ranges from 0 to 1 , with 1 representing the greatest severity. ${ }^{13}$ High psychiatric severity was defined as a score $>0.38 .{ }^{14}$ Other measures used in this study included the Treatment Services Review, ${ }^{15}$ the Thoughts about Abstinence Scale, ${ }^{16}$ the HIV Risk-taking Behavior Scale, ${ }^{17}$ and standard demographic information.

Self-reported data collected from participants were supplemented with data from several administrative sources, including state chemical dependency (CD) treatment records, felony and gross misdemeanor arrest records from the Washington State Patrol, and medical costs and utilization (including ED visits, inpatient hospital admissions, and outpatient medical visits) from encounter and billing records maintained by the medical center where the study took place. We also identified a number of chronic conditions for each participant using International Classification of Diseases, Ninth Revision (ICD-9), codes from medical records and the Chronic Illness and Disability Payment System. ${ }^{18}$ Data for the 2 years before baseline were available for all administrative measures.

\section{Data Analysis}

Demographic, medical, psychiatric, substance use/ treatment, and other psychosocial characteristics for the 3 DAST-10 drug use severity subgroups were compared with descriptive statistics. $\chi^{2}$ Tests were used for proportions, analysis of variance for continuous variables meeting distributional as- sumptions for parametric statistics, and KruskalWallis tests for variables meeting distributional assumptions for nonparametric statistics. Post hoc tests were conducted to identify specific subgroup differences: Pairwise comparisons for proportions were adjusted using a Bonferroni correction; Tukey and Games-Howell tests were used for continuous measures. Statistical significance was evaluated at $P<.05$.

\section{Results}

\section{Description of the Overall Sample}

A descriptive summary of the overall sample's $(\mathrm{n}=868)$ baseline demographic, substance use/ treatment, and other psychosocial characteristics can be found in Table 1 . Approximately $70 \%$ of the sample was male, $55 \%$ were nonwhite, $81 \%$ were single, $91 \%$ were not working, and $30 \%$ reported being homeless $\geq 1$ nights in the past 3 months.

According to ASI responses, most participants admitted to using marijuana in the previous 30 days (76\%), $42 \%$ to using stimulants, $\sim 26 \%$ to using opiates, and $8 \%$ to intravenous drug use; $45 \%$ used $\geq 2$ drugs in the previous 30 days. Almost 69\% endorsed using alcohol in the previous 30 days, and $72 \%$ endorsed using nicotine. In the 2 years before study enrollment, state records indicated $17 \%$ had been admitted to CD treatment at least once, $8 \%$ had been admitted to detoxification services with no subsequent CD treatment admission, and $14 \%$ had been arrested for a felony or gross misdemeanor. About 37\% indicated a goal of total abstinence from drugs.

Medical and psychiatric characteristics of participants are summarized in Table 2. In the 2 years before study enrollment, participants had a large number (mean, >7) of coexisting chronic medical conditions and substantial service utilization; $62 \%$ had $\geq 1 \mathrm{ED}$ visits, $27 \%$ were hospitalized $\geq 1$ time with a preceding ED visit, and almost $92 \%$ received $\geq 1$ outpatient medical service. ASI responses revealed the majority of participants experienced psychiatric problems: $71 \%$ had received prescribed medication for psychological or emotional problems in their lifetime. Almost 64\% had at least 1 mental illness diagnosis in their medical record in the previous 2 years.

The 20 most frequently recorded ICD-9 diagnoses for the 848 participants for whom we had 
Table 1. Select Baseline Characteristics of Participants Overall and By 10-Item Drug Abuse Screening Test Drug Use Severity Subcategories

\begin{tabular}{|c|c|c|c|c|c|}
\hline \multirow[b]{2}{*}{ Characteristics } & \multirow[b]{2}{*}{$\begin{array}{c}\text { Overall } \\
(\mathrm{N}=868)\end{array}$} & \multicolumn{3}{|c|}{ DAST-10 Drug Use Severity Subcategory* } & \multirow[b]{2}{*}{$\begin{array}{c}P \\
\text { Value }\end{array}$} \\
\hline & & $\begin{array}{c}\text { Low } \\
(\mathrm{n}=278)\end{array}$ & $\begin{array}{l}\text { Intermediate } \\
(\mathrm{n}=328)\end{array}$ & $\begin{array}{l}\text { Substantial/Severe } \\
\qquad(\mathrm{n}=262)\end{array}$ & \\
\hline \multicolumn{6}{|l|}{ Demographics } \\
\hline Age, mean years (SD) & $47.76(10.89)$ & $48.73(11.69)$ & $48.28(10.83)$ & $46.09(9.89)$ & .01 \\
\hline Male sex & $604(70)$ & $183(66)$ & $235(72)$ & $186(71)$ & .25 \\
\hline Race $^{\ddagger}$ & & & & & .01 \\
\hline White & $386(45)$ & $143(52)$ & $132(41)$ & $111(43)$ & \\
\hline Black & $320(37)$ & $82(30)$ & $126(39)$ & $112(43)$ & \\
\hline Other & $150(18)$ & $49(18)$ & $65(20)$ & $36(14)$ & \\
\hline Hispanic & $72(9)$ & $19(7)$ & $25(8)$ & $28(12)$ & .16 \\
\hline Marital status & & & & & .04 \\
\hline Married/living with partner & $161(19)$ & $51(18)$ & $73(22)$ & $37(14)$ & \\
\hline Divorced/separated/widowed & $348(40)$ & $99(36)$ & $132(40)$ & $117(45)$ & \\
\hline Never married & $357(41)$ & $126(46)$ & $123(38)$ & $108(41)$ & \\
\hline Education & & & & & $<.001$ \\
\hline High school or less & $166(19)$ & $38(14)$ & $66(20)$ & $62(24)$ & \\
\hline High school graduate & $254(29)$ & $70(25)$ & $98(30)$ & $86(33)$ & \\
\hline Beyond high school & $447(52)$ & $170(61)$ & $163(50)$ & $114(44)$ & \\
\hline Employment status & & & & & .01 \\
\hline Working & $78(9)$ & $35(13)$ & $31(9)$ & $12(5)$ & \\
\hline $\begin{array}{l}\text { Unemployed/retired/in school/ homemaker/ } \\
\text { other }\end{array}$ & $238(27)$ & $84(30)$ & $89(27)$ & $65(25)$ & \\
\hline Disabled and unable to work & $551(64)$ & $159(57)$ & $208(63)$ & $184(70)$ & \\
\hline $\begin{array}{l}\text { Homeless in shelter or on street } \geq 1 \text { night in the } \\
\text { past } 90 \text { days }\end{array}$ & $263(30)$ & $42(15)$ & $91(28)$ & $130(50)$ & $<.001$ \\
\hline \multicolumn{6}{|l|}{ Substance use/treatment } \\
\hline ASI days most frequently used drug, mean $(\mathrm{SD})^{\S}$ & $13.82(11.00)$ & $12.25(11.00)$ & $14.35(11.08)$ & $14.84(10.77)$ & .01 \\
\hline ASI drug use composite score, mean $(\mathrm{SD})^{\mathbb{S} \|}$ & $0.11(0.10)$ & $0.06(0.05)$ & $0.10(0.09)$ & $0.19(0.12)$ & $<.001$ \\
\hline \multicolumn{6}{|l|}{ ASI drug use, any in the past 30 days $^{\pi /}$} \\
\hline Marijuana & $656(76)$ & $243(87)$ & $249(76)$ & $164(63)$ & $<.001$ \\
\hline Stimulants ${ }^{\pi /}$ & $362(42)$ & $40(14)$ & $141(43)$ & $181(69)$ & $<.001$ \\
\hline Cocaine & $325(37)$ & $34(12)$ & $130(40)$ & $161(61)$ & $<.001$ \\
\hline Amphetamines & $63(7)$ & $7(3)$ & $20(6)$ & $36(14)$ & $<.001$ \\
\hline Opiates $^{\text {II }}$ & $228(26)$ & $33(12)$ & $93(28)$ & $102(39)$ & $<.001$ \\
\hline Heroin & $59(7)$ & $1(0)$ & $13(4)$ & $45(17)$ & $<.001$ \\
\hline $\begin{array}{l}\text { Methadone and other opiates/analgesics not } \\
\text { prescribed }\end{array}$ & $208(24)$ & $33(12)$ & $86(26)$ & $89(34)$ & $<.001$ \\
\hline Sedatives/hypnotics/tranquilizers & $72(8)$ & $7(3)$ & $28(9)$ & $37(14)$ & $<.001$ \\
\hline Other drugs ${ }^{\S \#}$ & $51(6)$ & $9(3)$ & $19(6)$ & $23(9)$ & .02 \\
\hline$\geq 2$ Drugs used in the past 30 days $\$$ & $389(45)$ & $63(23)$ & $152(46)$ & $174(66)$ & $<.001$ \\
\hline Intravenous drug use in the past 30 days & $72(8)$ & $5(2)$ & $15(5)$ & $52(20)$ & $<.001$ \\
\hline Goal of total abstinence from drugs ${ }^{\S * *}$ & $323(37)$ & $40(14)$ & $124(38)$ & $159(61)$ & $<.001$ \\
\hline ASI alcohol use composite score, mean (SD) $)^{\|}$ & $0.15(0.20)$ & $0.08(0.13)$ & $0.13(0.18)$ & $0.25(0.25)$ & $<.001$ \\
\hline ASI alcohol use, any in the past 30 days & $598(69)$ & $182(65)$ & $220(67)$ & $196(75)$ & .04 \\
\hline Nicotine use, any in the past 30 days & $620(72)$ & $169(61)$ & $242(74)$ & $209(80)$ & $<.001$ \\
\hline \multicolumn{6}{|l|}{$\mathrm{CD}$ treatment services ${ }^{\dagger \dagger}$} \\
\hline Admitted to CD treatment & $147(17)$ & $17(6)$ & $44(14)$ & $86(34)$ & $<.001$ \\
\hline $\begin{array}{l}\text { Detoxification (not followed by CD } \\
\text { treatment) }\end{array}$ & $65(8)$ & $9(3)$ & $14(4)$ & $42(17)$ & $<.001$ \\
\hline
\end{tabular}




\begin{tabular}{|c|c|c|c|c|c|}
\hline \multirow[b]{2}{*}{ Characteristics } & \multirow[b]{2}{*}{$\begin{array}{c}\text { Overall } \\
(\mathrm{N}=868)\end{array}$} & \multicolumn{3}{|c|}{ DAST-10 Drug Use Severity Subcategory* } & \multirow[b]{2}{*}{$\begin{array}{c}P \\
\text { Value }^{\dagger}\end{array}$} \\
\hline & & $\begin{array}{c}\text { Low } \\
(\mathrm{n}=278)\end{array}$ & $\begin{array}{l}\text { Intermediate } \\
(\mathrm{n}=328)\end{array}$ & $\begin{array}{l}\text { Substantial/Severe } \\
\quad(\mathrm{n}=262)\end{array}$ & \\
\hline \multicolumn{6}{|l|}{ Other Psychosocial } \\
\hline$\geq 1$ Arrest for felony or gross misdemeanor ${ }^{\dagger \dagger}$ & $122(14)$ & $17(6)$ & $45(14)$ & $60(24)$ & $<.001$ \\
\hline $\mathrm{HIV}$ risk-taking score, mean $(\mathrm{SD})^{\S \S}$ & $3.35(4.21)$ & $2.57(3.16)$ & $3.12(3.67)$ & $4.46(5.45)$ & $<.001$ \\
\hline ASI family/social composite score, mean (SD) $)^{\S}$ & $0.17(0.22)$ & $0.12(0.18)$ & $0.17(0.21)$ & $0.22(0.25)$ & $<.001$ \\
\hline
\end{tabular}

Data are reported as no. (\%) of participants unless otherwise indicated. Missing values are not included in this table.

${ }^{*}$ Of 10,337 individuals screened, 1,621, or about $16 \%$, were eligible. Of these, 520 declined to participate and 154 were excluded for other reasons (eg, left during the consent process). The remaining 947 provided consent. Of these 947,79 were excluded (22 because of current participation in chemical dependency (CD) treatment, 9 because they had acute suicidality or psychosis, 8 because they had no drug use in the past 3 months, 3 because they were not a primary care patient, and 2 because they had insufficient contact information); 32 declined to participate; and 3 were excluded for other reasons, leaving 868 as the final sample.

${ }^{\dagger} P$ value based on $\chi^{2}$, analysis of variance, or Kruskal-Wallis test.

${ }^{\ddagger}$ Assessed by self-report using National Institutes of Health reporting categories for federally funded clinical research.

${ }^{\S}$ Excludes use of alcohol or nicotine.

"Addiction Severity Index-Lite (ASI) composite scores range from 0 to 1, with 1 indicating greatest problem severity.

IIASI drug use groups reported are not mutually exclusive.

\#"Other drugs" can include all other abused medications (eg, antihistamines, antidepressants) or drugs of abuse (eg, hallucinogens, inhalants) not included in the existing categories.

** From the Thoughts about Abstinence measure, which is used to assess one's goal for changing drug use (no goal; controlled use; occasional use; temporary abstinence; total abstinence, slip is possible; total abstinence, never use again). The reported "goal of total abstinence from drugs" includes "total abstinence, never use again" and "total abstinence, slip is possible."

${ }^{+\dagger}$ Administrative data were available for 848 participants in the 2 years before study enrollment.

${ }^{\$}$ Human immunodeficiency virus (HIV) risk-taking score ranges from 0 to 50 , with 50 indicating greatest HIV risk.

DAST-10, 10-item Drug Abuse Screening Test; SD, standard deviation.

medical data over the 2 years before study enrollment are summarized in Table 3 . The most frequent diagnosis was hypertension, followed by tobacco use disorder, depressive disorder, pain in limb, and chronic pain. Only $4 \%$ of these episodes of care were covered by a commercial payer; the remaining were covered by Medicaid (38\%), Medicare (27\%), or unsponsored/uncompensated care $(31 \%)$.

\section{Severity of Drug Use}

DAST-10 drug severity subgroups were compared based on demographic, substance use/treatment, and other psychosocial, medical, and psychiatric variables. The results of these comparisons are summarized in Tables 1, 2, 4, and 5 .

\section{Substantial/Severe Drug Use Severity}

Results indicated that patients with the highest drug use severity differed from patients with intermediate and low drug use severity as follows: They were younger; they were more likely to be homeless; to have used stimulants, opiates, $\geq 2$ drugs, and drugs intravenously in the previous 30 days; and to have a goal of total abstinence from drugs. They were less likely to have used marijuana in the previous 30 days. In the 2 years before study enrollment, a higher proportion was admitted to CD treatment and/or detoxification services, and a higher proportion had at least 1 arrest for a felony or gross misdemeanor. They had ASI composite scores indicating more difficulties in the family/social domains, and they had higher scores on the HIV Risk-taking Behavior Scale.

In the 2 years before study enrollment, patients with the highest drug use severity had a higher mean number of ED visits, mean ED costs, and mean number of inpatient hospital admissions preceded by an ED visit than patients with intermediate or low drug use severity. They were also more likely to have an ASI psychiatric severity composite score $>0.38^{19}$ and to have received prescribed medication for psychological or emotional problems in their lifetime than patients with intermediate or low drug use severity.

\section{Low Drug Use Severity}

Patients with low drug use severity differed from intermediate and substantial/severe drug-using 
Table 2. Medical and Psychiatric Characteristics of Participants Overall and By 10-Item Drug Abuse Screening Test Drug Use Severity Subcategories

\begin{tabular}{|c|c|c|c|c|c|}
\hline \multirow[b]{2}{*}{ Characteristics } & \multirow[b]{2}{*}{$\begin{array}{c}\text { Overall } \\
(\mathrm{N}=868)\end{array}$} & \multicolumn{3}{|c|}{ DAST-10 Drug Use Severity Subcategory* } & \multirow[b]{2}{*}{$\begin{array}{c}P \\
\text { Value }^{\dagger}\end{array}$} \\
\hline & & $\begin{array}{c}\text { Low } \\
(\mathrm{n}=278)\end{array}$ & $\begin{array}{l}\text { Intermediate } \\
(\mathrm{n}=328)\end{array}$ & $\begin{array}{l}\text { Substantial/Severe } \\
\quad(\mathrm{n}=262)\end{array}$ & \\
\hline \multicolumn{6}{|l|}{ Medical } \\
\hline $\begin{array}{l}\text { CDPS medical conditions, } \\
\text { mean (SD) }\end{array}$ & $7.42(3.78)$ & $7.26(3.86)$ & $7.54(3.52)$ & $7.45(4.00)$ & .66 \\
\hline \multicolumn{6}{|l|}{ Emergency department } \\
\hline$\geq 1$ visit & $528(62)$ & $140(51)$ & $208(64)$ & $180(71)$ & $<.001$ \\
\hline Mean visits (SD) & $2.52(4.27)$ & $1.49(2.11)$ & $2.26(3.40)$ & $3.94(6.20)$ & $<.001$ \\
\hline Mean cost (SD), US\$ & $1,347.69(2,436.81)$ & $847.87(1,641.90)$ & $1,203.20(2,152.93)$ & $2,069.52(3,212.05)$ & $<.001$ \\
\hline Median visits & $1.00(3.00)$ & $1.00(2.00)$ & $1.00(3.00)$ & $2.00(5.00)$ & \\
\hline Median cost, US\$ & $363.81(1,565.18)$ & $56.12(1,006.36)$ & $265.76(1,502.64)$ & $896.02(2,792.61)$ & \\
\hline \multicolumn{6}{|l|}{ Outpatient medical } \\
\hline$\geq 1$ visit & $780(92)$ & $245(90)$ & $307(95)$ & $228(90)$ & .04 \\
\hline Mean visits (SD) & $18.94(17.98)$ & $21.22(18.62)$ & $19.25(17.37)$ & $16.08(17.72)$ & .004 \\
\hline Mean cost (SD), US\$ & $7,114.62(8,918.87)$ & $7,752.36(8,694.52)$ & $6,826.72(6,964.86)$ & $6,796.55(11,110.28)$ & .36 \\
\hline Median visits & $14.00(22.00)$ & $17.00(25.00)$ & $15.00(21.00)$ & $10.00(18.00)$ & \\
\hline Median cost, US\$ & $4,563.84(8,060.05)$ & $5,417.63(8,647.68)$ & $4,677.26(7,146.79)$ & $3,911.40(6,509.43)$ & \\
\hline \multicolumn{6}{|l|}{$\begin{array}{l}\text { Inpatient preceded by an ED } \\
\text { visit }\end{array}$} \\
\hline$\geq 1$ Inpatient admission & $227(27)$ & $63(23)$ & $73(22)$ & $91(36)$ & $<.001$ \\
\hline Mean admissions (SD) & $0.44(0.94)$ & $0.34(0.77)$ & $0.37(0.87)$ & $0.62(1.14)$ & .001 \\
\hline Mean cost (SD), US\$ & $6,055.14(22,329.21)$ & $4,788.08(17,591.21)$ & $4,128.98(13,675.27)$ & $9,876.45(32,908.00)$ & .005 \\
\hline Median admissions & $0.00(1.00)$ & $0.00(0.00)$ & $0.00(0.00)$ & $0.00(1.00)$ & \\
\hline Median cost, US\$ & $0.00(2,928.17)$ & $0.00(0.00)$ & $0.00(0.00)$ & $0.00(5,990.48)$ & \\
\hline \multicolumn{6}{|l|}{ Psychiatric } \\
\hline $\begin{array}{l}\text { High psychiatric severity, ASI } \\
\text { psychiatric status } \\
\text { composite score }>0.38^{\ddagger}\end{array}$ & $470(54)$ & $114(41)$ & $175(53)$ & $181(69)$ & $<.001$ \\
\hline $\begin{array}{l}\text { ASI psychiatric status } \\
\text { composite score, mean } \\
(\mathrm{SD})^{\ddagger \mathbb{S} \|}\end{array}$ & $0.38(0.24)$ & $0.30(0.24)$ & $0.38(0.24)$ & $0.47(0.21)$ & $<.001$ \\
\hline $\begin{array}{l}\geq 1 \text { Mental illness ICD-9 } \\
\text { diagnosis }\end{array}$ & $542(64)$ & $160(59)$ & $210(65)$ & $172(68)$ & .08 \\
\hline $\begin{array}{l}\text { Prescribed medication for } \\
\text { psychological or emotion } \\
\text { problems, over lifetime }\end{array}$ & $619(71)$ & $181(65)$ & $231(70)$ & $207(79)$ & $<.001$ \\
\hline
\end{tabular}

Data are reported as no. (\%) of participants unless otherwise indicated. Missing values are not included in this table.

*Administrative data were available for 848 participants for the 2 years before study enrollment unless otherwise noted.

${ }^{\dagger} P$ value is based on $\chi^{2}$, analysis of variance, or Kruskal-Wallis test.

${ }^{\ddagger}$ Data were available for 868 participants.

${ }^{\$}$ ASI composite scores range from 0 to 1 , with 1 indicating greatest problem severity.

$\|_{\text {A score }}>0.38$ was defined as high psychiatric severity ${ }^{14}$ and represents a value of 1 standard deviation (SD) (0.22) above the mean (0.16) of the psychiatric severity composite score for nearly 3900 outpatients receiving chemical dependency treatment and assessed by the ASI. ${ }^{19}$ The 0.38 cutoff exceeds the 0.22 cutoff identified by Cacciola et $\mathrm{al}^{20}$ as the level likely to be associated with a psychiatric disorder among patients admitted to chemical dependency treatment.

ASI, Addiction Severity Index; CDPS, Chronic Illness and Disability Payment System;DAST-10, 10-item Drug Abuse Screening Test; ED, emergency department; SD, standard deviation; ICD-9, International Classification of Diseases, Ninth Revision.

patients in that they were more likely to be educated, less likely to be homeless, and more likely to have lower ASI drug use composite scores (reflecting less serious drug problems). Most reported use of marijuana and reported little use of other drugs, and they were less likely to have a goal of abstinence from drugs. In the 2 years before study enrollment, these patients were less likely to have been admitted to CD treatment or to have been arrested for a felony or misde- 
Table 3. Twenty Most Frequently Recorded ICD-9 Diagnosis Codes for Trial Participants*

\begin{tabular}{lc}
\hline & $\begin{array}{c}\text { Participants, } \\
\mathrm{n}(\%)\end{array}$ \\
\hline Hiagnosis Category & $397(47)$ \\
Tobacco use disorder & $388(46)$ \\
Depressive disorder, not elsewhere classified & $361(43)$ \\
Pain in limb & $296(35)$ \\
Chronic pain, not elsewhere classified & $256(30)$ \\
Lumbago & $244(29)$ \\
Cough & $217(26)$ \\
Hyperlipidemia, not elsewhere classified/not & $207(24)$ \\
$\quad$ otherwise specified & $201(24)$ \\
Vaccine for influenza & $195(23)$ \\
Physical therapy, not elsewhere classified & $193(23)$ \\
Abdominal pain (unspecified site) & $192(23)$ \\
Chest pain, not otherwise specified & $187(22)$ \\
Viral hepatitis C (unspecified without & \\
mention of hepatic coma) & $184(22)$ \\
Lack of housing & $180(21)$ \\
Diabetes mellitus (without mention of & \\
complication, type 2 or unspecified, not & \\
stated as controlled) & $179(21)$ \\
Esophageal reflux & $175(21)$ \\
Backache, not otherwise specified & $151(18)$ \\
Anxiety state, not otherwise specified & $146(17)$ \\
Palpitations & $141(17)$ \\
Acute upper respiratory infection, not & \\
otherwise specified & \\
\hline
\end{tabular}

*Diagnosis categories are based on 2927 distinct International Classification of Diseases, Ninth Revision, codes, based on data collected for 848 participants in the 2 years before study enrollment.

meanor. They were also less likely to score in the high psychiatric range of the ASI psychiatric composite and were more likely to have lower ASI social/family composite scores (reflecting fewer problems).

\section{Intermediate Drug Use Severity}

Patients in the intermediate drug use severity subgroup were in between and significantly different from both patients with low and patients with severe drug use severity in the proportion reporting being homeless; using marijuana, stimulants, opiates, or $\geq 2$ drugs; having a goal of abstinence from drugs; being admitted to CD treatment; being arrested for a felony or misdemeanor in the 2 years before study enrollment. They also had significantly different ASI family/social composite scores.

They were not significantly different from patients with low drug use severity in their intrave- nous drug use or alcohol use in the 30 days before baseline; in inpatient medical admissions in the 2 years before baseline; or in the proportion of patients who reported taking prescribed medication for psychological or emotional problems in their lifetime. They were not significantly different from patients with substantial/severe drug use severity in their ED use or in their reported use of nonprescribed methadone and other opiates/analgesics/ sedatives.

\section{Discussion}

Individuals who used illicit drugs and who were seeking primary care within a safety net medical setting had multiple coexisting social, psychiatric, and health problems, similar to observations in studies focused on treatment-seeking drug users, ${ }^{3,5}$ studies based on national surveys, ${ }^{2}$ and studies of such individuals presenting at EDs. ${ }^{8}$ This study is distinguished from previous efforts in that it was conducted in primary care clinics with patients who were not explicitly seeking substance abuse treatment. It is also distinctive in its focus on examining characteristics across the range of drug use severity as a strategy to identify clinical needs across the drug-using population.

As a group, participants in our study had significant medical needs. They had an unusually large number of chronic comorbid medical conditions, averaging 7 Chronic Illness and Disability Payment System categories; the average number for disabled Medicaid beneficiaries is $<2 .{ }^{18}$ Although a relatively young group with a mean age of 48 years, the most frequent diagnoses reflected serious chronic conditions such as hypertension. Clearly, this is a population that will need ongoing medical care.

\section{Severity of Drug Use}

Patients with the highest level of drug use severity were significantly different from their less severe drug-using counterparts in ways that can interfere with seeking appropriate medical treatment as well as understanding and adhering to treatment recommendations, such as having high levels of homelessness (50\%), psychiatric severity (70\%), and low family support. Because of their drug use historysuch as use of opiates, stimulants, and sedatives-as well as recent intravenous drug use, it is not surprising that they were experiencing more legal consequences than their counterparts with lower drug 
Table 4. Post Hoc Results for Statistically Significant Baseline Characteristics in Table 1

\begin{tabular}{|c|c|c|c|}
\hline \multirow[b]{2}{*}{ Characteristic } & \multicolumn{3}{|c|}{ Post Hoc $P$ Value } \\
\hline & $\begin{array}{c}\text { Substantial/Severe } \\
\text { vs Low }\end{array}$ & $\begin{array}{l}\text { Substantial/Severe } \\
\text { vs Intermediate }\end{array}$ & $\begin{array}{c}\text { Intermediate } \\
\text { vs Low }\end{array}$ \\
\hline \multicolumn{4}{|l|}{ Demographics } \\
\hline Age $^{*}$ & .01 & .04 & ns \\
\hline Race $^{\dagger}$ & .02 & ns & .05 \\
\hline Marital status $^{\dagger}$ & ns & ns & ns \\
\hline Education $^{\dagger}$ & $<.001$ & ns & .04 \\
\hline Employment status $^{\dagger}$ & .002 & ns & ns \\
\hline Homeless in shelter or on the street $\geq 1$ night in the past 90 days $^{\dagger}$ & $<.001$ & $<.001$ & $<.001$ \\
\hline \multicolumn{4}{|l|}{ Substance use/treatment } \\
\hline ASI days most frequently used drug* & .02 & ns & ns \\
\hline ASI drug use composite score ${ }^{\ddagger}$ & $<.001$ & $<.001$ & $<.001$ \\
\hline \multicolumn{4}{|l|}{ ASI drug use, any in the past 30 days $^{\dagger}$} \\
\hline Marijuana & $<.001$ & .001 & $<.001$ \\
\hline Stimulants & $<.001$ & $<.001$ & $<.001$ \\
\hline Cocaine & $<.001$ & $<.001$ & $<.001$ \\
\hline Amphetamines & $<.001$ & .005 & .10 \\
\hline Opiates & $<.001$ & .02 & $<.001$ \\
\hline Heroin & $<.001$ & $<.001$ & $<.001$ \\
\hline Methadone and other opiates & $<.001$ & ns & $<.001$ \\
\hline Sedatives/hypnotics/tranquilizers & $<.001$ & ns & .005 \\
\hline Other drugs & .019 & ns & ns \\
\hline$\geq 2$ Drugs used in the past 30 days $^{\dagger}$ & $<.001$ & $<.001$ & $<.001$ \\
\hline Intravenous drug use in past 30 days $^{\dagger}$ & $<.001$ & $<.001$ & ns \\
\hline Goal of total abstinence from drugs ${ }^{\dagger}$ & $<.001$ & $<.001$ & $<.001$ \\
\hline ASI alcohol use composite score ${ }^{\ddagger}$ & $<.001$ & $<.001$ & .001 \\
\hline Alcohol use, any in the past 30 days $^{\dagger}$ & .05 & ns & ns \\
\hline Nicotine use, any in the past 30 days $^{\dagger}$ & $<.001$ & ns & .002 \\
\hline \multicolumn{4}{|l|}{$\mathrm{CD}$ treatment services ${ }^{\dagger}$} \\
\hline Admitted to CD treatment & $<.001$ & $<.001$ & .009 \\
\hline Detoxification (not followed by CD treatment) & $<.001$ & $<.001$ & ns \\
\hline \multicolumn{4}{|l|}{ Other Psychosocial } \\
\hline$\geq 1$ Arrest for felony or gross misdemeanor ${ }^{\dagger}$ & $<.001$ & .008 & .007 \\
\hline HIV risk-taking score ${ }^{\ddagger}$ & $<.001$ & .002 & ns \\
\hline ASI family/social composite score ${ }^{\ddagger}$ & $<.001$ & .02 & .01 \\
\hline
\end{tabular}

*Data are Tukey-adjusted $P$ values.

${ }^{\dagger}$ Data are Bonferroni-adjusted $P$ values.

${ }^{\ddagger}$ Data are Games-Howell-adjusted $P$ values.

ASI, Addiction Severity Index Lite; CD, chemical dependency; HIV, human immunodeficiency virus; ns, not significant.

use severity; almost $24 \%$ had a recent history of $\geq 1$ felony or gross misdemeanor arrest.

Patients with the highest drug use severity frequently treated their medical problems by using intensive and costly ED and inpatient hospital services; they had twice the number of ED visits and about double the mean ED cost relative to patients with low levels of drug use severity. They had a history of more frequent inpatient hospital admissions preceded by an ED visit—a pattern often characterized as reflecting unplanned admissions to a hospital. Almost $17 \%$ of this group had a recent history of being admitted to detoxification services with no subsequent treatment, another crisis service. It is noteworthy that costs of medical services received by participants in our study were paid almost exclusively by public funds: Medicare, Medicaid, or unsupported/uncompensated care.

Despite the multiplicity and seriousness of problems concentrated in the substantial/severe drug 
Table 5. Post Hoc Results for Statistically Significant Medical and Psychiatric Characteristics in Table 2

\begin{tabular}{|c|c|c|c|}
\hline \multirow[b]{2}{*}{ Characteristics } & \multicolumn{3}{|c|}{ Post Hoc $P$ Values } \\
\hline & $\begin{array}{l}\text { Substantial/Severe } \\
\text { vs Low }\end{array}$ & $\begin{array}{l}\text { Substantial/Severe } \\
\text { vs Intermediate }\end{array}$ & $\begin{array}{l}\text { Intermediate } \\
\text { vs Low }\end{array}$ \\
\hline \multicolumn{4}{|l|}{ Medical } \\
\hline \multicolumn{4}{|l|}{ ED } \\
\hline$\geq 1 \mathrm{ED}$ visit* & $<.001$ & ns & .004 \\
\hline Mean visits ${ }^{\dagger}$ & $<.001$ & $<.001$ & .002 \\
\hline Mean costs ${ }^{\dagger}$ & $<.001$ & .001 & ns \\
\hline \multicolumn{4}{|l|}{ Outpatient medical } \\
\hline$\geq 1$ Outpatient visit* & ns & ns & ns \\
\hline Mean visits ${ }^{\ddagger}$ & .004 & ns & ns \\
\hline \multicolumn{4}{|l|}{ Inpatient preceded by an ED visit } \\
\hline$\geq 1$ Inpatient admissions* & .003 & .001 & ns \\
\hline Mean admissions ${ }^{\dagger}$ & .003 & .01 & ns \\
\hline Mean costs ${ }^{\dagger}$ & ns & .03 & ns \\
\hline \multicolumn{4}{|l|}{ Psychiatric } \\
\hline $\begin{array}{l}\text { High psychiatric severity, ASI psychiatric status } \\
\text { composite score }>0.38^{*}\end{array}$ & $<.001$ & $<.001$ & .007 \\
\hline ASI psychiatric status composite score ${ }^{\dagger}$ & $<.001$ & $<.001$ & $<.001$ \\
\hline $\begin{array}{l}\text { Prescribed medication for psychological or emotional } \\
\text { problems, over lifetime* }\end{array}$ & $<.001$ & $<.001$ & ns \\
\hline
\end{tabular}

*Data are Bonferroni-adjusted $P$ values.

${ }^{\dagger}$ Data are Games-Howell-adjusted $P$ values.

${ }^{\ddagger}$ Data are Tukey-adjusted $P$ values.

ASI, Addiction Severity Index Lite; ED, emergency department; ns, not significant.

use severity subgroup, this subgroup had the highest proportion of patients with a goal of future abstinence from drugs (almost 61\%) and also contained the highest proportion of patients admitted to $\mathrm{CD}$ treatment in the previous 2 years (34\%). Although not conclusive, these findings open the possibility that this subset of illicit drug users may be among those most open to treatment recommendations. We recommend future research examine this.

Their multiple comorbidities suggest a need for specialized addiction and psychiatric care as well as primary care services that can address the medical consequences of substantial/severe drug use, including intravenous drug use. Access to buprenorphine or methadone treatment for addiction is particularly relevant for safety net clinics that serve patients with severe drug problems. ${ }^{21}$ Unstable lifestyles associated with substantial/severe drug use may require coordination with social services.

By contrast, patients with the lowest DAST-10 scores were primarily users of marijuana, with little reported use of stimulants and opioids coupled with more stable lifestyles than those in the intermediate or substantial/severe subgroups. They were less likely to be homeless, to have co-occurring psychiatric problems, to have been arrested for a felony or gross misdemeanor in the 2 years before study enrollment, or to report having family/social problems. They also had fewer ED visits. On one hand, this set of characteristics suggests a population that may be easier to treat in primary care than those with more severe problem drug use. But few patients with low drug use severity had the goal of abstinence from drugs, and, correspondingly, few sought treatment for their drug use in the 2 years before study enrollment. They may be experiencing fewer consequences of their problem drug use and, as such, may not be as open to recommendations for specialized CD treatment as might patients who are experiencing more frequent and severe consequences.

Characteristics of patients with intermediate drug use severity fell between patients with substantial/severe and low drug use severity on most measures. As such, selective application of interventions suggested for patients with high and low drug use severity may be useful with them. 


\section{Psychiatric Severity}

Psychiatric severity was most pronounced among patients with high drug use severity (almost 70\%), although the percentages of patients with low and intermediate drug use severity with high psychiatric severity were still noteworthy: $41 \%$ and $53 \%$, respectively. In this study the most frequently reported mental health-related diagnostic code was depressive disorder (Table 3). Collaborative care approaches integrating behavioral health into primary care have shown promise in effectively treating populations who present with depression, particularly those who are among the least or moderately severe. ${ }^{22-24}$ A collaborative care approach is consistent with emphasis in the ACA on integrated services ${ }^{7}$ and with medical societies such as the American Board of Family Medicine, which has explicitly identified integrated behavioral health care as a core principle of the patient-centered medical home (PCMH). ${ }^{25,26}$ Despite support, evidence suggests that implementation of integrative models is still in the early stage of development. ${ }^{27}$ This places primary care safety net clinics in a key position to develop a range of responses that are locally effective to serve patients with problem drug use. In so doing, results of their work may have the potential to inform national efforts to establish PCMHs and to implement the ACA.

\section{Identifying Patients With Problem Drug Use}

The DAST-10 was used to identify patients with problem drug use in this study. It is short, easy to administer and score, and it maps well to American Society of Addiction Medicine placement criteria. However, it bears less relationship to ICD and Diagnostic and Statistical Manual of Mental Disorders diagnoses, which may interfere with acceptance of its placement guidelines as the basis for coverage decisions by public and thirdparty payers. Other instruments used to screen for problem drug use include the Alcohol, Smoking and Substance Involvement Screening Test and the Addiction Severity Index. ${ }^{19,28}$

\section{Strengths and Limitations}

Strengths of this study are the relatively large sample size $(\mathrm{n}=868)$ and that the sample was drawn from primary care. This combination is unusual when viewed in the context of the existing literature. There are also limitations. First, we had no comparison group; thus all analyses are based on within-group comparisons. As such, they are descriptive and exploratory in nature and are best regarded as a rich source of hypotheses for the design of future studies rather than being definitive. Second, results from this sample are only generalizable to public sector health care or safety net settings, although the exclusion criteria used in this study may have inadvertently resulted in a disadvantaged sample that has milder characteristics than the target population. Third, our use of the ASI composite score to define psychiatric severity had important limitations. This measure was not designed to serve as a formal, standalone psychiatric assessment, and it does not provide psychiatric diagnostic information. Nonetheless, it provided an important opportunity to identify provisional relationships that can be more definitively explored in future studies. Finally, medical records may have been incomplete in their documentation of medical and psychiatric diagnoses; such omissions may serve to complicate care provision.

\section{Conclusions}

The purpose of this study was to examine baseline characteristics of people across the range of problem drug use to identify their clinical needs. Results confirmed that, as a group, patients with problem drug use had an unusually high number of co-occurring medical conditions, many serious and chronic, suggesting they are likely to need ongoing medical care. Results also indicated that patients with the highest drug use severity were unusual in the frequency and degree of psychiatric and substance abuse problems they present; their unstable lifestyles characterized by homelessness, frequent arrests, and low social/family support; as well as their frequent use of ED and inpatient medical services. Such patients are likely to require specialized psychiatric and substance abuse care; ongoing medical care that is equipped to address the consequences of severe drug use, including intravenous drug use; and coordination with social services. Patients with low drug use severity were primarily users of marijuana, with little reported use of other drugs, less psychiatric comorbidity, and more stable lifestyles than those with more severe drug use severity. Because of their milder symptoms, these patients may benefit from a collaborative care 
model that integrates psychiatric and substance abuse care in the primary care setting. Patients with intermediate drug use severity may benefit from selective application of interventions suggested for patients with the highest and lowest drug use severity. Safety net primary care clinics are currently in a key position to develop a range of responses that are locally effective to serve patients with problem drug use and, in so doing, may also inform national efforts to establish PCMHs and to implement the ACA.

\section{References}

1. National Drug Intelligence Center. The economic impact of illicit drug use on American society. Washington, DC: US Department of Justice; 2011.

2. Compton WM, Thomas YF, Stinson FS, Grant BF. Prevalence, correlates, disability, and comorbidity of DSM-IV drug abuse and dependence in the United States: results from the national epidemiologic survey on alcohol and related conditions. Arch Gen Psychiatry 2007;64:566-76.

3. Mertens JR, Lu YW, Parthasarathy S, Moore C, Weisner CM. Medical and psychiatric conditions of alcohol and drug treatment patients in an HMO: comparison with matched controls. Arch Intern Med 2003;163:2511-7.

4. Regier DA, Farmer ME, Rae DS, et al. Comorbidity of mental disorders with alcohol and other drug abuse. Results from the Epidemiologic Catchment Area (ECA) Study. JAMA 1990;264:2511-8.

5. Onyeka IN, Beynon CM, Uosukainen H, et al. Coexisting social conditions and health problems among clients seeking treatment for illicit drug use in Finland: the HUUTI study. BMC Public Health 2013;13:380.

6. Deck D, Wiitala W, McFarland B, et al. Medicaid coverage, methadone maintenance, and felony arrests: outcomes of opiate treatment in two states. J Addict Dis 2009;28:89-8102.

7. Nardone M, Snyder S, Paradise J. Integrating physical and behavioral health care: promising medicaid models. Menlo Park (CA): Kaiser Family Foundation; 2014.

8. Blow FC, Walton MA, Barry KL, et al. Alcohol and drug use among patients presenting to an inner-city emergency department: a latent class analysis. Addict Behav 2011;36:793-800.

9. Roy-Byrne P, Bumgardner K, Krupski A, et al. Brief intervention for problem drug use in safety-net primary care settings: a randomized clinical trial. JAMA 2014;312:492-501.

10. Krupski A, Joesch JM, Dunn C, et al. Testing the effects of brief intervention in primary care for problem drug use in a randomized controlled trial: rationale, design, methods. Addict Sci Clin Pract 2012;7:27.

11. Skinner HA. The drug abuse screening test. Addict Behav 1982;7:363-71.

12. Skinner HA. Guide for using the Drug Abuse Screening Test (DAST). 1982. Available from: http://www.emcdda.europa.eu/attachements.cfm/ att 61480 EN DAST\%202008.pdf. Accessed September 2, 2014.

13. Cacciola JS, Alterman AI, McLellan AT, Lin YT, Lynch KG. Initial evidence for the reliability and validity of a "Lite" version of the Addiction Severity Index. Drug Alcohol Depend 2007;87:297-302.

14. Alterman AI, McLellan AT, Shifman RB. Do substance abuse patients with more psychopathology receive more treatment? J Nerv Ment Dis 1993;181: 576-82.

15. Cacciola JS, Alterman AI, Lynch KG, Martin JM, Beauchamp ML, McLellan AT. Initial reliability and validity studies of the revised Treatment Services Review (TSR-6). Drug Alcohol Depend 2008;92: 37-47.

16. Hall SM, Havassy BE, Wasserman DA. Commitment to abstinence and acute stress in relapse to alcohol, opiates, and nicotine. J Consult Clin Psychol 1990;58:175-81.

17. Darke S, Hall W, Heather N, Ward J, Wodak A. The reliability and validity of a scale to measure HIV risk-taking behaviour among intravenous drug users. AIDS 1991;5:181-5.

18. Kronick R, Gilmer T, Dreyfus T, Lee L. Improving health-based payment for Medicaid beneficiaries: CDPS. Health Care Financ Rev 2000;21:29-64.

19. McLellan AT, Cacciola JC, Alterman AI, Rikoon SH, Carise D. The Addiction Severity Index at 25: origins, contributions and transitions. Am J Addict 2006;15:113-24.

20. Cacciola JS, Pecoraro A, Alterman AI. Development of ASI psychiatric severity cut-off scores to identify co-occurring psychiatric disorders. Int J Ment Health Addiction 2008;6:77-92.

21. West S, O’Neal K, Graham C. A meta-analysis comparing the effectiveness of buprenorphine and methadone. J Subst Abuse 2000;12:405-14.

22. Archer J, Bower P, Gilbody S, et al. Collaborative care for depression and anxiety problems. Cochrane Database Syst Rev 2012;10:CD006525.

23. Chan YF, Huang H, Bradley K, Unutzer J. Referral for substance abuse treatment and depression improvement among patients with co-occurring disorders seeking behavioral health services in primary care. J Subst Abuse Treat 2014;46:106-12.

24. Bauer AM, Azzone V, Goldman HH, et al. Evaluating the implementation of collaborative depression management in community-based primary care clinics. Psychiatr Serv 2011;62:1047-53.

25. Baird M, Blount A, Brungardt S, et al. The development of joint principles: integrating behavioral 
health care into the patient-centered medical home. Ann Fam Med 2014;12:183.

26. Working Party Group on Integrated Behavioral Healthcare. The development of joint principles: integrating behavioral health care into the patientcentered medical home. Fam Syst Health 2014;32: 153 .
27. Kessler R, Miller BF, Kelly M, et al. Mental health, substance abuse, and health behavior services in patient-centered medical homes. J Am Board Fam Med 2014;27:637-44.

28. Humeniuk R. Validation of the alcohol, smoking and substance involvement screening test (ASSIST). Addiction 2008;103:1039-47. 